\title{
PEMANFAATAN SAMPAH KULIT KAWISTA (LIMONIA ACIDISSIMA) MENJADI BRIKET BIOARANG SEBAGAI BAHAN BAKAR A LTERNATIF
}

\author{
Linda Sekar Utami ${ }^{1 *}$, Johri Sabaryati ${ }^{2}$ \\ ${ }^{1 * \& 2}$ Dosen Progran Studi Pendidikan Fisika Universitas Muhammadiyah Mataram \\ Corresponding author : \\ E-mail : lindasekarutami@gmail.com
}

Diterima 2 Juli 2018, Disetujui 5 Juli 2018

\begin{abstract}
ABSTRAK
Penelitian ini bertujuan untuk menentukan nilai kalor yang terkandung dalam briket yang terbuat dari kulit kawista. Kulit Kawista dikarbonisasi terlebih dahulu menjadi arang. Proses pembuatan briket dengan menggunakan arang yang divariasikan komposisinya menggunakan binder tapioka,. Diperoleh bahwa kandungan binder mempengaruhi karakteristik dari briket. Penggunaan tapioka memberikan nilai kalor lebih baik. Nilai kalor paling besar ditunjukkan oleh briket dengan penambahan binder tapioka $10 \%$, yaitu sebesar $5073,69 \mathrm{kal} / \mathrm{g}$.
\end{abstract}

Kata Kunci: Briket Bioarang, Nilai Kalor, Energi Alternatif.

\section{PENDAHULUAN}

Peranan energi dalam aktivitas manusia memiliki arti yang sangat penting.Energi seakan menjadi primadona dalam kehidupan mahluk hidup. Energi tidak muncul begitu saja tanpa ada sebab dan sumbernya. Begitu juga dengan dengan energi panas yang merupakan salah satu bentuk energi. Energi panas muncul karena ada perubahan fisik dari sumber energi sehingga muncul panas. Sumber energi panas ini dapat berupa kayu bakar,minyak tanah,gas dan sebagainya. Sumber energi inilah yang sering diburu manusia. Manusia seakan tidak mempedulikan asal sumber energi tersebut. Akibatnya persediaan sumber energi inipun semakin menipis.

Melihat kecenderungan ini maka perlu dipikirkan suatu cara untuk menggali sumber energi baru. Sumber energi lain yang banyak terdapat di pedesaan antara lain sekam padi,daun kering,rumput,alang-alang,batang jagung kering dan bahan lain yang umumnya sebagai hasil buangan atau limbah pertanian. Sangat di sayangkan kalau limbah pertanian hanya dibuang begitu saja tanpa digunakan.

Sebagai mana diketahui bahwa minyak bumi merupakan salah satu bentuk kekayaan alam yang tidak dapat diperbaharui. Karenanya besar kemungkinan bahwa lambat laun persediaannya semakin menipis dan akhirnya habis (Umboh, 1996).

Akhir-akhir ini harga bahan bakar minyak dunia meningkat pesat yang berdampak pada meningkatnya harga jual bahan bakar minyak termasuk minyak tanah. Minyak tanah di Indonesia yang selama ini yang telah dikurangi subsidinya oleh pemerintah menjadi beban yang sangat berat bagi masyarakat Indonesia. Untuk mengantisipasi kenaikan harga BBM dalam hal ini minyak tanah diperlukan bahan bakar alternatif yang murah dan mudah didapat.

Salah satu alternatif untuk mengatasi menipisnya persediaan minyak bumi adalah dengan cara memanfaatkan kulit buah kawista. Banyak cara yang dapat digunakan untuk memanfaatkan barang yang tidak berguna ini. Sebelum digunakan kulit buah kawista di proses terlebih dahulu menjadi briket dalam arti dimatangkan atau dikarbonkan. Sebelum dimanfatkan sebagai sumber energi limbah tersebut diperoses atau diolah menjadi bioarang terlebih dahulu (Widarto L.dan Suryanta,1995).

\section{METODE PENELITIAN \\ Jenis Penelitian}

Penelitian murni adalah salah satu jenis penelitian sosial yang memiliki orientasi pada bidang akademis. Jenis penelitian ini tidak bertujuan untuk memberikan solusi atas suatu masalah atau fenomena sosial tertentu. Ciri utama dari penelitian ini adalah banyak digunakan dalam lingkungan akademis, memiliki tingkat abstrak yang tinggi, manfaatnya tidak dapat dirasakan secara langsung, serta mengembangkan ide, teori atau gagasan. Kelebihan dari penelitian murni adalah dapat dijadikan fondasi dalam pembuatan kebijakan dan dapat digunakan sebagai dasar pemikiran 
dalam pemecahan masalah. Sedangkan kelemahannya adalah waktu dan dana yang diperlukan untuk mengadakan penelitian ini relatif lama, serta dinilai cenderung kurang efektif karena manfaatnya baru dapat dirasakan dalam jangka panjang.

\section{Studi Kepustakaan}

Studi kepustakaan yaitu dengan cara mempelajari literature - literature yang berkaitan dengan masalah yang dibahas, baik melalui perpustakaan maupun melalui internet.

\section{Eksperiman}

Eksperimen yaitu dengan cara menyelidiki besar kalor yang terdapat pada kulit kawista ( Limonia Acidissima), tepung tapioka serta campuran keduanya yang diuji dengan menggunakan bomb kalorimeter.

\section{Waktu dan Tempat Penelitian}

Penelitian ini dilaksanakan selama bulan maret 2018 di Laboratorium Kimia bahan pangan jurusan nutrisi dan makanan ternak fakultas peternakan Universitas Mataram.

\section{Alat dan Bahan Penelitian}

\section{Bahan Penelitian} penelitian ini adalah :

Alat - Alat yang digunakan dalam

1. Kaleng

2. Pengaduk.

3. Neraca.

4. Gelas ukur.

5. Penumbuk.

6. Blender

7. Ayakan 100 mesh.

8. Cetakan Stainless.

9. Pengepress.

10. Oven.

11. Termometer

Bahan - bahan yang digunakan pada penelitian ini adalah :

\section{Kulit buah Kawista \\ 2. Tepung tapioka \\ 3. Air}

\section{Metode Pembuatan Arang}

Sampah kulit buah kawista yang diperoleh dikeringkan. Setelah kering lalu diarangkan. Pembakaran dilakukan di dalam kaleng (gambar 3.1) agar tidak mengakibatkan sampah kering menjadi abu. Pertama-tama dimasukkan daun kering sedikit saja kemudian dibakar, selanjutnya tambahkan sampah kulit buah kawista yang kering tadi ke dalam kaleng minyak sampai $2 / 3$ kaleng lalu aduk- aduk untuk menghasilkan arang yang rata. Jika asap mati maka proses pengarangan sudah jadi, kemudian isi kaleng disiram dengan air lalu arang basah yang dihasilkan dijemur sampai kering. Setelah kering ditumbuk dan diayak dengan 40 mesh yaitu 40 lubang dalam 1 inc $^{2}$.

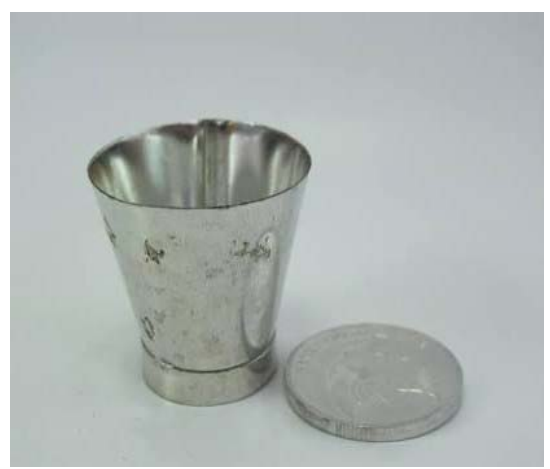

Gambar 1. Alat tempat pembakaran arang.

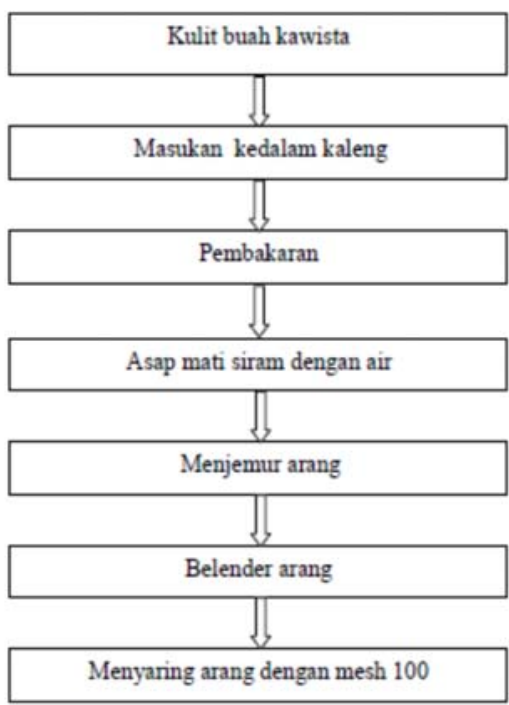

Gambar 2. Alur pembuatan arang dari kulit buah kawista.

\section{Metode Pembuatan Briket}

Pembuatan briket adalah dengan mencampur bubuk arang yang dipilih dari hasil ayakan, dengan tujuan mendapatkan briket yang padat kemudian dicampur dengan bahan perekat. Setelah tercampur rata selanjutnya dicetak dengan alat cetak dan di beri tekanan sebesar 5,66 MPa selama 30 detik. Setelah briket dicetak selanjutnya dioven pada suhu $80{ }^{\circ} \mathrm{C}$ sampai kering. Diagram alur pembuatan briket dapat dilihat pada gambar 3

Alat cetak berdiameter $1,5 \mathrm{~cm}$ dan tinggi 6 $\mathrm{cm}$. Maka pembuatan briket dengan variasi penambahan binder disesuaikan dengan volume alat cetak. Data penambahan binder dapat dilihat pada tabel 1 
Tabel 1. Pembuatan Briket dengan Variasi Binder Tapioka

\begin{tabular}{|c|c|c|}
\hline Sampel & $\begin{array}{c}\text { Fraksi massa } \\
\text { tapioka (\%) }\end{array}$ & $\begin{array}{c}\text { Fraksi massa } \\
\text { arang (\%) }\end{array}$ \\
\hline 1 & 10 & 90 \\
\hline 2 & 15 & 85 \\
\hline 3 & 20 & 80 \\
\hline 4 & 25 & 75 \\
\hline 5 & 30 & 70 \\
\hline
\end{tabular}

Alur Pembuatan Briket dengan Binder Tapioka



Gambar 3. Alur pembutan briket dengan binder tapioka

\section{Pengujian Briket}

Dalam penelitian ini dilakukan uji kalor untuk mengetahui berapa besar energi yang dapat dihasilkan oleh briket dari kulit buah kawista.

\section{Pengujian Nilai Kalor Briket}

Pengujian nilai kalor briket bioarang dilakukan dengan menggunakan alat Adiabatic Oxygen Bomb Calorimeter yang terdapat di Laboratorium Kimia Bahan Pakan Fakultas Peternakan Unram. Prinsip pengukuran adalah berdasarkan jumlah panas yang diukur dalam kalori dan dihasilkan apabila sampel briket dioksidasi sempurna dalam bomb kalorimeter (yang disebut energi total dari briket). Proses pembakaran oleh oksigen di dalam bomb kalorimeter, terdapat pengotor berupa gas nitrogen. Hal ini terbukti pada saat pencucian embun sisa pembakaran ditetesi metil merah, larutan akan berwarna merah. Hal ini terjadi karena larutan yang terbentuk adalah asam nitrat ( $\mathrm{HNO}_{3}$ ). Selanjutnya kadar nitrogen diuji dengan cara titrasi, Pada proses titrasi yaitu dengan menggunakan larutan natrium karbonat $\left(\mathrm{Na}_{2} \mathrm{CO}_{3}\right)$. Reaksi pada proses titrasi adalah:

$$
2 \mathrm{HNO}_{3}+\mathrm{Na}_{2} \mathrm{CO}_{3} \rightarrow 2 \mathrm{NaNO}_{3}+\mathrm{H}_{2} \mathrm{O}+\mathrm{CO}_{2} \text {. }
$$

Ketika larutan sudah bening, titrasi dihentikan, kemudian diukur volume natrium karbonat yang digunakan. Selain hasil titrasi, sebagai koreksi adalah sisa kawat setelah pembakaran dengan bomb kalorimeter mengalikan dengan tetapan 2,3 kal $/ \mathrm{cm}$.

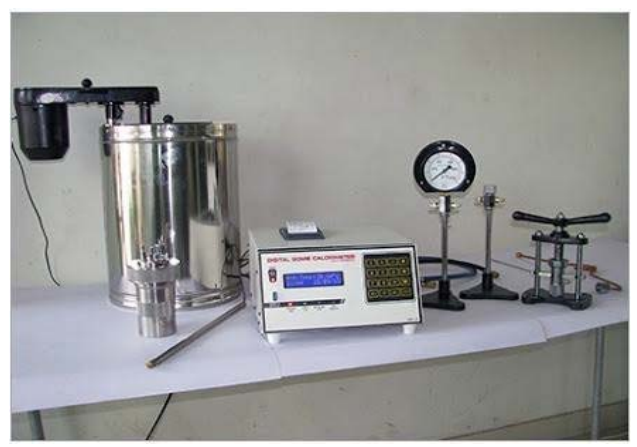

Gambar 4. Bomb Kalorimeter

\section{Persiapan Uji Kalor}

1. Persiapan Briket

- Membersihkan cawan.

- Menimbang briket yang akan dibakar (maksimal 1,5 g)

2. Persiapan bucket

- Mengisi bucket dengan aquadest 2 liter.

3. Persiapan Bomb

- Membersihkan bomb dengan aquadest.

- Mengeringkan bomb.

- Memotong kawat pemantik sepanjang minimal $10 \mathrm{~cm}$ maksimal $15 \mathrm{~cm}$ dan memasang pada tempatnya.

- Memasang cawan yang telah diisi briket pada tempatnya dan mengatur kawat pemantik sehingga menyentuh briket.

- Memasang cawan pada bomb, mengeraskannya dengan screw cap.

- Mengisi bomb dengan oksigen pada tekanan $30 \mathrm{~atm}$.

- Memasang bucket yang telah diisi aquadest pada tempatnya.

- Mengambil bomb dengan penjepit dalam posisi tegak agar briket tidak berubah posisi.

- Memasukkan bomb dalam bucket dan mengatur terminal nut pada tempatnya.

- Mengambil penjepit. 
- Memasang penutup bak bomb kalorimeter pada tempatnya.

- menghubungkan pengaduk aquadest dengan dinamo dengan karet gelang.

- Menghubungkan dinamo dengan sumber listrik.

- Memeriksa temperatur aquadest.

- Menghubungkan bomb kalorimeter dengan ignition unit, kemudian menghubungkannya dengan sumber tegangan PLN.

4. Pembakaran.

- Memeriksa semua peralatan.

- Menyiapkan tabel pencatat data.

- Menghidupkan dinamo selama 5 menit dan mencatat temperatur tiap menitnya.

- Tepat 5 menit briket dibakar dengan menekan tombol merah pada ignation unit.

- Mencatat temperatur tiap 1 menit dan diakhiri jika temperatur setelah 6 kali pencatatan menunjukkan angka yang sama kemudian menekan tombol vibra untuk menggerakkan sampel agar dapat terjadi perubahan suhu.

- Mematikan dinamo bila alat mengeluarkan bunyi nyaring yang menandakan bahwa suhu tidak dapat naik lagi.

5. Pembongkaran bomb.

- Melepaskan pengaduk dari dinamo dan melepas tutup bomb kalorimeter.

- Melepaskan kedua terminal nutsnya dan meletakkannya di tempat yang bersih, mengangkat bomb dari bucket dengan penjepit.

- Mengeluarkan sisa gas hasil pembakaran dari dalam bomb dengan memutar valve knop pada tutup bomb.

- Melepaskan screw cap dan mengangkat penutup bomb lalu diletakkan di tempat yang bersih.

- Mengambil cawan dan mencuci bagian dalamnya dengan menyemprotkan aquadest, dimana air cucian tersebut ditampung dalam gelas ukur.

- Mencuci bomb dengan aquadest dan menjadikan satu dengan sisa cucian cawan.
- Titrasi air cucian dengan larutan $\mathrm{Na}_{2} \mathrm{CO} 3$ dengan indikator methyl merah sebanyak 3 tetes, dengan reaksi yang terjadi adalah: $2 \mathrm{HNO}_{3}+\mathrm{Na}_{2} \mathrm{CO}_{3} \rightarrow 2 \mathrm{NaNO}_{3}+$ $\mathrm{H}_{2} \mathrm{O}+\mathrm{CO}_{2}$

- Melepaskan sisa kawat pemantik, untuk kemudian diluruskan dan diukur panjangnya.

\section{HASIL DAN PEMBAHASAN Pengaruh Kandungan Binder Terhadap Nilai} Kalor

Uji Kalor dilakukan untuk mengetahui besar energi panas atau kalor yang dapat dihasilkan oleh briket bioarang. Briket arang dengan binder tapioka dan variasi kandungan binder $(10 \%-30 \%$ massa) telah diuji nilai kalornya (lampiran I). Halaman 32. Data nilai kalor untuk briket dengan binder tapioka ditunjukan pada tabel 2 .

Tabel 2. Tabel nilai kalor briket dengan binder tapioka.

\begin{tabular}{|l|c|c|}
\hline No & Fraksimassa binder & NilaiKalor $(\mathrm{kal} / \mathrm{g})$ \\
\hline 1. & 10 & 5073,69 \\
\hline 2. & 15 & 4855,16 \\
\hline 3. & 20 & 4782,16 \\
\hline 4. & 25 & 4810,45 \\
\hline 5. & 30 & 4185,89 \\
\hline \multicolumn{2}{|c|}{ Dengan penambahan binder tapioka } \\
\hline
\end{tabular}
dapat mempengaruhi nilai kalor briket. Semakin banyak penambahan binder tapioka maka kalor yang dihasilkan semakin menurun. Hal ini dapat dilihat pada gambar 5

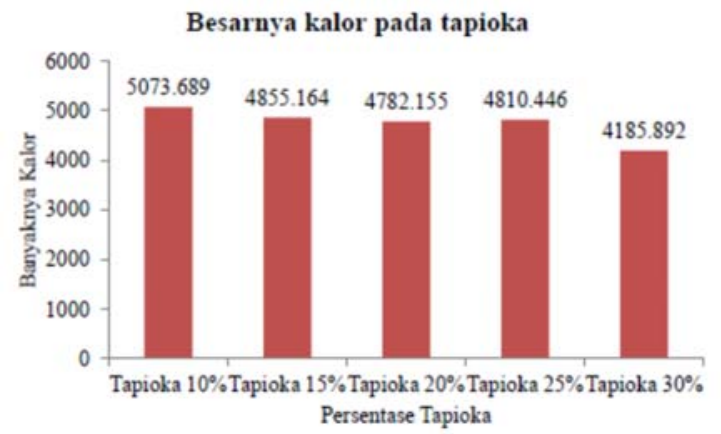

Gambar 5. Grafik nilai kalor terhadap persentase binder tapioca Besar kalor yang dihasilkan dari bioarang adalah $>5000 \mathrm{kal} / \mathrm{g}$ sedangkan dari biomasa $>3000 \mathrm{kal} / \mathrm{g}$ (Widarto, 1995).

Dalam penelitian ini dilakukan karbonisasi agar menghasilakan kalor yang 
besar. Menurut peraturan Menteri NO.47 tahun 2006 besar kalor briket terkarbonisasi yang memenuhi standar nasional adalah $>3500 \mathrm{kal} / \mathrm{g}$. Dari penelitian ini diperoleh bahwa briket yang dibuat dengan campuran tapioka memeiliki nilai kalor yang memenuhi standar nasional. Nilai kalor yang paling besar adalah briket dengan binder tapioka

\section{SIMPULAN DAN SARAN}

\section{Simpulan}

1. Briket dengan binder tapioka telah berhasil dibuat. Kandungan binder mempengaruhi bentuk briket yang dihasilkan khususnya kandungan energi. Semakin banyak kandungan binder maka nilai kalor yang dihasilkan semakin kecil.

2. Diperoleh variasi nilai kalor (4185,8925073,689) kal/. Dengan membandingkan hasil penelitian dengan Peraturan Menteri No.47 tahun 2006, briket yang telah dibuat telah memenuhi syarat nilai kalor standar nasional (>3500 kal/g). Dalam penelitian ini yang dioptimalkan adalah pemanfaatan sampah kulit buah kawista, oleh sebab itu berdasarkan penelitian ini, briket yang paling optimal untuk diproduksi adalah briket yang menggunakan binder tapioka $10 \%$.

\section{Saran}

Dalam penelitian berikutnya disarankan:

1. Untuk mendapatkan hasil yang lebih baik perlu dia dakan penelitian penelitian lebih lanjut menggunakan biomassa dan sampah - sampah organik lainnya.

2. Perlu dipikirkan tentang tungkuh yang digunakan dalam pemanfaatan briket ini sebagai sumber energi alternatif.

\section{DAFTAR PUSTAKA}

Adan, Ismun Uti. 1998. Membuat Briket. Yogyakarta : Kanisius Anonim. 2016 (Limonia Acidissima)

Anonim. $2000 \quad$ Penuntun Analisis Proxsimat.Mataram : Fakultas Peternakan Universitas Mataram

Eddy Harmadi, Tjokrowisastro dan Budi Utomo, Kuku Widodo. 1990. Teknik Pembakaran Dasar dan Bahan Bakar. Surabaya : ITS

Muin, Syamsir A. 1986. Pesawat - pesawat Konversi Energi I (Katel Uap). Jakarta : Rajawali Pers.
Sekar Utami, Linda. 2011. Pemanfaatan sampah daun manggis menjadi Briket Bioarang sebagai bahan bakar Alternatif. Bandung ITB

Sutanto, j. 1982. Termodinamika Terapan : Yogyakarta : Kanisius

Umboh, Andry Harist. 1996. Anekah Tungkuh Sederhana. Jakarta : Penebar Swadaya 